\title{
Infecção por leptospira em bovinos e sua associação com transtornos reprodutivos e condições climáticas
}

\author{
[Leptospiral infection in bovine and its association with reproductive failure \\ and climatic conditions]
}

\author{
A.L.B.B. Mineiro ${ }^{1,4}$, E.E.A.Bezerra ${ }^{1}$, S.A. Vasconcellos $^{2}$, F.A.L.Costa ${ }^{3 *}$, N.A. Macedo ${ }^{3}$ \\ ${ }^{1}$ Aluno de pós-graduação - CCA - UFPI - Teresina, PI \\ ${ }^{2}$ Faculdade de Medicina Veterinária e Zootecnia - USP - São Paulo, SP \\ ${ }^{3}$ Centro de Ciências Agrárias - UFPI \\ Campus da Socopo \\ 64046-550 - Teresina-PI
}

\begin{abstract}
RESUMO
Realizou-se estudo sorológico, por meio do teste de soroaglutinação microscópica, utilizando antígenos vivos, para pesquisa de aglutininas anti-leptospiras em bovinos de leite na Microrregião de Parnaíba, PI, em dois períodos do ano: estações seca e chuvosa. Das 1975 amostras analisadas, pertinentes a 16 rebanhos, 1044 $(52,9 \%)$ mostraram-se positivas a pelo menos um sorovar e todos os rebanhos apresentaram animais reagentes. A prevalência variou entre $25 \%$ e $81 \%$. O sorovar de maior prevalência foi Hardjo reagindo em 39,5\%, seguido de Wolffi com 26,7\% e Hebdomadis com 12,2\%. Os sorovares mais freqüentes foram Hardjo e Wolffi presentes em 100\% dos rebanhos. Foram ainda encontrados animais reagentes aos sorovares Australis, Bratislava, Autumnalis, Butembo, Icterohaemorrhagiae, Shermani e Patoc. Houve correlação positiva entre a proporção de animais sororreagentes para leptospirose e pluviometria, mas não para temperatura. Foi constatada associação entre infecção e ocorrência de transtornos reprodutivos, e o sorovar que apresentou maior associação foi o Hardjo.
\end{abstract}

Palavras-chave: bovino, transtornos reprodutivos, leptospirose

\begin{abstract}
This study was carried out by serologic sampling (microscopic agglutination test, living antigens) for antileptospiral antibodies in dairy farms of Parnaiba microrregion, state of Piaui, Brazil, during dry and rainny seasons. All 16 flocks were infected and 1044 out of 1975 sera samples (52.9\%) were positive for at least one serovar. Higher prevalence was serovar Hardjo (39.5\%) folowed by Wolffi (26.7\%) and Hebdomadis (12.2\%). Hardjo and Wolffi were found in all flocks. Serovars Australis, Bratislava, Autumnalis, Butembo, Hebdomadis, Icterohaemorrhagiae, Hardjo, Wolffi, Shermani and Patoc, were also present. A positive correlation between prevalence of infection and pluviometric was detected, but temperature ratios. Association between infection and reproductive failures was evidenced mainly regarding Hardjo serovar.
\end{abstract}

Keywords: bovine, reproductive failure, leptospirosis

\section{INTRODUÇÃO}

As leptospiroses constituem um grupo importante de zoonoses de ampla difusão em todo o mundo (Plank e Dean, 2000). É causada por bactéria da ordem Spirochaetales gênero

Recebido em 21 de julho de 2006

Aceito em 25 de julho de 2007

*Autor para correspondência (corresponding author)

E-mail: fassisle@ufpi.br
Leptospira sendo L. interrogans a principal espécie patogênica (Costa, 1995; Farr, 1995).

No Brasil, a leptospirose é endêmica e está presente no rebanho bovino em quase todos os estados da federação. Os sorovares detectados em bovinos estão restritos a Hardjo (genótipo 
hardjoprajitno), Pomona, Icterohaemorrhagiae, Wolffi, Goiano e Guaicurus (Lilenbaum, 1996; Araújo et al., 2005). No estado do Piauí, há registros da presença de bovinos, caninos, ovinos e humanos reagentes a leptospiras (Macedo et al., 1996; Costa Jr. et al., 2004; Carvalho, 2005)

A doença determina elevados prejuízos econômicos à pecuária bovina, pelo comprometimento do desempenho reprodutivo dos rebanhos acometidos, em que repetições de cio, abortamentos e queda na produção leiteira são as principais evidências clínicas em rebanhos soropositivos (Vasconcelos et al., 1997; Cortez et al., 2006). A infecção por leptospira tem sido associada a transtornos reprodutivos em animais, especialmente bovinos (Smith et al., 1997; Alonso - Andigoberry et al., 2001; Cortez et al., 2006). As regiões tropicais e subtropicais são as mais favoráveis à infecção (Oliveira et al., 2003) e tem-se notado uma correlação positiva entre a freqüência de casos de leptospirose e os índices pluviométricos (Guimarães, 1983).

Considerando as reações cruzadas, devidas à presença de sorovares saprófitas comuns no ambiente rural, que podem induzir a erros em estudos de prevalência com apenas uma tomada de amostras (Vasconcelos et al., 1997), ainda que aleatória, o presente estudo teve por objetivo verificar a variação sazonal de títulos de anticorpos em bovinos naturalmente expostos à infecção, em dois períodos do ano, sua associação com transtornos reprodutivos e com pluviometria e temperatura.

\section{MATERIAL E MÉTODOS}

A pesquisa foi realizada na bacia leiteira de Parnaíba, situada em região litorânea, norte do estado do Piauí. A temperatura encontra-se na isoterma $28^{\circ} \mathrm{C}\left(23^{\circ} \mathrm{C}-33,6^{\circ} \mathrm{C}\right)$. A umidade relativa encontra-se na isoieta 1200 , mas muito próxima a de 1400, com período chuvoso concentrado a partir de janeiro, estendendo-se até março (Monteiro, 1968).

Foram sorteados aleatoriamente bovinos de uma população de cerca de 2000 animais, de 16 propriedades da região. A estratificação foi determinada segundo o tamanho do rebanho, para uma prevalência esperada de $50 \%$, precisão desejada de $95 \%$ e nível de confiança de $95 \%$, o que resultou em 384 cabeças. Foram realizados testes de tuberculose, brucelose e rinotraqueíte infecciosa, excluindo-se do estudo os animais positivos. Consideraram-se os seguintes transtornos reprodutivos: abortamento, retenção de placenta, morte de bezerro nas primeiras 72 horas sem causa aparente e repetição de cio. Nos rebanhos examinados, não é realizada vacinação contra leptospirose.

As colheitas de sangue ocorreram em duas ocasiões: final da estação seca (outubro, novembro e dezembro) e final da estação das chuvas (abril, maio e junho), abrangendo o segundo semestre de 2001 e o primeiro de 2002.

O meio de Ellinghausen, McCullough, Johnson, Harris modificado (EMJH) foi utilizado para o crescimento dos antígenos empregados na reação de soroaglutinação microscópica. Adotou-se a metodologia da microtécnica descrita por Galton et al. (1965). O sorovar registrado foi o que apresentou maior título. No caso de o maior título ter sido detectado para dois ou mais sorovares, o animal foi excluído da análise, nos testes de associação, mas não do estudo do título médio geométrico.

A diluição dos soros foi feita em solução tamponada estéril de Sörensen (Santa Rosa, 1970). A leitura foi realizada em microscópio de campo escuro com objetiva de 10x. A ocorrência de aglutinação indicou a presença de anticorpos nos soros. A intensidade da aglutinação foi classificada em: $1=25 \% ; 2=50 \% ; 3=75 \% ; 4=$ $100 \%$. Os soros classificados de 2 a 4 foram submetidos a uma segunda prova de soroaglutinação microscópica para titulação de anticorpos com os sorovares identificados como reagentes.

Os antígenos empregados na reação de soroaglutinação microscópica incluíram uma coleção de 22 estirpes de L. interrogans e duas de L. biflexa.

Para cada sorovar encontrado foi calculado, independente do título, mês a mês, o título médio geométrico (TMG) (Thrusfield, 2004). A confiança do título médio geométrico foi determinada pelo cálculo da diferença do desviopadrão e do coeficiente de variação para as duas estações do ano. A associação entre prevalência e estação do ano e transtornos reprodutivos foi determinada pelo cálculo da odds ratio e qui 
quadrado. Utilizou-se o teste de Pearson para a análise de correlação entre infecção e dados climáticos (Sackett et al., 1985; Drumond e Silva, 1998). Adotou-se o nível de significância de 0,05 .

\section{RESULTADOS E DISCUSSÃO}

A percentagem de reagentes para Leptospira interrogans foi de 52,9\%. A maior prevalência de infecção foi encontrada para o sorovar Hardjo $(39,5 \%)$, presente em $100 \%$ dos rebanhos, seguida de Wolffi e Hebdomadis. Os sorovares com menor prevalência foram Pomona, Grippotyphosa e Icterohaemorrhagiae (2,0\%). Os sorovares Australis, Bratislava, Autumnalis, Butembo, Icterohaemorrhagiae, Shermani e Patoc mostraram-se presentes em valores inferiores a $10 \%$, mas estavam bem distribuídos nos rebanhos. Os sorovares mais freqüentes, também, revelaram maiores títulos $(1: 3.200 \mathrm{e}$ 1:6.400), exceto Shermani, com título máximo de 3.200, mas que apareceu em apenas 5,6\% das amostras examinadas. Os sorovares menos prevalentes mostraram títulos de 1:400 a 1:1600. Observou-se que todos os rebanhos examinados encontravam-se infectados por, pelo menos, um sorovar e como a vacinação para leptospirose não é realizada, pode-se admitir que tais valores referem-se à infecção natural. A percentagem de reagentes $(52,9 \%)$ foi próxima à encontrada por Fávero et al. (2001), para o estado do Piauí (56,0\%), com 95,4\% de rebanhos infectados. Molnár et al. (1999), no Pará, encontraram prevalência superior $(65,9 \%)$ em 417 amostras.

Reações para mais de um sorovar foram encontradas em 10 das 24 variantes sorológicas utilizadas, com títulos aglutinantes de 1:100 ou mais; Sejroe, com 66,2\% (691/1044), foi o sorogrupo mais freqüente; no sorogrupo, predominou o sorovar Hardjo, com freqüência de $59,6 \%(412 / 691)$ seguido de Wolffi, com 40,4\% (279/691). Os demais sorogrupos e suas variantes sorológicas somaram $33,8 \%$ (353/1044).

Alguns sorovares considerados importantes para bovinos, como Pomona, Grippotyphosa e Icterohaemorrhagiae, mostraram baixa prevalência $(2,0 \%)$, ou nem sequer reagiram, o que é condizente com os achados de Araújo et al. (2005) em Minas Gerais e Lilenbaum et al.
(1995) no Rio de Janeiro, que não encontraram nenhuma amostra reagente a esses sorovares e Molnár et al. (1999) que, no Pará, encontraram baixa prevalência (3,0\%). Fávero et al. (2001), também, não relataram a presença desses sorovares infectando bovinos no Piauí.

O fato de o sorovar Hardjo ter sido o mais encontrado $(39,5 \%)$ está em conformidade com a maioria dos inquéritos sorológicos realizados em bovinos (Ellis 1994; Vasconcellos et al., 1997; Fávero et al., 2001; Homem et al., 2000; Araújo et al., 2005); tais inquéritos o consideram o mais difundido e causador de abortamentos nessa espécie, com evidências sorológicas em todo o mundo. Em 20 estados brasileiros e no distrito federal, Fávero et al (2001) encontraram o sorovar Hardjo como predominante. No estado do Piauí, Hardjo estava presente em $66,5 \%$ dos positivos, seguido de Wolffi $13,3 \%$ e pomona, $5,1 \%$ (Fávero et al., 2001). Os títulos encontrados neste trabalho foram de no máximo 6400 , o que sugere que aqueles animais se encontravam, de fato, infectados.

O segundo sorovar mais prevalente foi Wolffi $(26,7 \%)$, com títulos que variaram de 1:100 a 1:6400, o qual estava presente em $100 \%$ dos rebanhos pesquisados. Silva et al. (1994) e Araújo et al. (2005) encontraram 57\%, 13,2\% de positivos para esse sorovar, respectivamente. $\mathrm{O}$ sorovar Wolffi tem sido referido em inquéritos sorológicos nos Estados Unidos da América (Miller et al., 1991) e no México (Covarrubias e Ruiz, 1995); existe, todavia, a hipótese de que tais registros seriam resultados de reações cruzadas com o sorovar Hardjo, pois ambos estão incluídos no sorogrupo, Sejroe (Faine, 1982) e, dessa forma, compartilham determinantes antigênicos. Saliente-se, por outro lado, que o critério empregado no presente estudo, com análise da relação freqüência/título, pelo cálculo do título médio geométrico, teve como objetivo minimizar a participação daquela interferência.

O estudo pareado das prevalências mensais, segundo as estações do ano (Tab. 1), permite observar um aumento da infecção no período chuvoso. De fato, no período de janeiro/fevereiro/março, registraram-se os maiores índices de precipitação pluviométrica e os menores da temperatura ambiente para a microrregião, o que leva a acreditar que a 
infecção instalada nesse período seja responsável pela considerável proporção de bovinos reagentes, com reflexos sobre a persistência de títulos aglutinantes para o período de outubro/novembro/dezembro, época seca do ano. Destaca-se que houve correlação positiva $(r=$ $0,6708)$ entre infecção e pluviometria, mas não entre infecção e temperatura $(r=-0,9350)$. O erro-padrão da amostra $(\mathrm{EPA}=0,0112)$, determinado pelo cálculo da dispersão dos indivíduos ao longo da mesma, indica a confiança dos dados do ponto de vista de erro à amostragem.

Tabela 1. Bovinos sororreagentes para Leptospira sp., segundo o momento da colheita e o clima na microrregião de Parnaíba, PI

\begin{tabular}{|c|c|c|c|c|c|c|c|c|c|c|c|c|c|c|}
\hline \multirow[b]{2}{*}{ Reagentes } & \multicolumn{6}{|c|}{ Seca } & \multicolumn{6}{|c|}{ Chuva } & \multirow[b]{2}{*}{ Total } & \multirow[b]{2}{*}{$\%$} \\
\hline & $\begin{array}{l}\text { Out./ } \\
2001\end{array}$ & $\%$ & $\begin{array}{l}\text { Nov/ } \\
2001\end{array}$ & $\%$ & $\begin{array}{l}\text { Dez./ } \\
2001\end{array}$ & $\%$ & $\begin{array}{l}\text { Abr// } \\
2002\end{array}$ & $\%$ & $\begin{array}{c}\text { Maio/ } \\
2002\end{array}$ & $\%$ & $\begin{array}{l}\text { Jun./ } \\
2002\end{array}$ & $\%$ & & \\
\hline Sim & 175 & 49,16 & 130 & 38,35 & 133 & 40,42 & 170 & 50,44 & 210 & 68,62 & 226 & 73,38 & 1044 & 52,89 \\
\hline Não & 181 & 50,84 & 209 & 61,65 & 196 & 59,58 & 167 & 49,56 & 96 & 31,38 & 82 & 26,62 & 931 & 47,11 \\
\hline Total & 356 & 100,00 & 339 & 100,00 & 329 & 100,00 & 337 & 100,00 & 306 & 100,00 & 308 & 100,00 & 1975 & 100,00 \\
\hline
\end{tabular}

A diminuição da proporção de soropositivos, entre os períodos chuvoso e seco, sugere que, na microrregião, o período chuvoso atua como fator favorecedor da persistência de leptospiras no ambiente. Resultado diverso ao obtido por Miller et al. (1991) em bovinos dos Estados Unidos da América, mas similares aos encontrados por Alves et al. (1996) em caprinos no estado da Paraíba e Carpio et al. (2000) em alpacas (Lama pacos) em Puno, no altiplano peruano. Dessa forma, enquanto as condições climáticas se mantiverem propícias, espera-se que leptospiras permaneçam viáveis para infectar novos hospedeiros, seja animal silvestre, doméstico ou o homem (Niang et al., 1995).

Em caprinos, no estado da Paraíba, Alves et al. (1996) constatou proporções de reagentes positivos na área litorânea (clima tropical) mais elevados do que no interior do estado (semiárido).

É preciso considerar que as colheitas foram realizadas em outubro/novembro/dezembro de 2001 e abril/maio/junho de 2002, de forma intermitente, com pelo menos duas abordagens, uma na estação seca e outra na chuvosa, e que anticorpos para leptospiras permaneceram detectáveis à sorologia, pelo menos no período considerado. As colheitas foram realizadas justamente no final de cada estação, época em que há maior representatividade de condições ambientais "típicas" da estação considerada (Faine, 1982).
O estudo do título médio geométrico (TMG) mostra predomínio para Hardjo, na estação seca. O TMG é maior nas chuvas para os sorovares Australis, Icterohemorrhagiae, Wolffi, Shermani e Patoc, e maior na seca para Bratislava, Autumnalis, Butembo, Hebdomadis e Hardjo (Tab. 2). Contudo, os sorovares Hardjo e Wolffi, foram, respectivamente, os mais prevalentes. $\mathrm{O}$ sorovar Hardjo não só está melhor disperso na população como apresenta títulos mais elevados que os demais. Se admitirmos que a oportunidade de infecção é maior nas chuvas e que a prova de soroaglutinação microscópica detecta melhor IgG que $\operatorname{IgM}$, isto é, infecção tardia que recente, poder-se-ia presumir que a infecção produz anticorpos mais duradouros para aqueles sorovares com maior TMG nas secas. De fato, para Hardjo e Hebdomadis há maior prevalência nas chuvas, mas maior TMG na seca, enquanto para Wolffi há maior prevalência na seca e maior TMG na chuva. Mesmo assim, o sorovar Hardjo apresenta maior prevalência que Wolffi nas duas estações e maior TMG na seca.

Observou-se correlação entre positivos para leptospira e transtornos reprodutivos $(\mathrm{r}=0,61)$ (Fig. 1). Se considerar que foram eliminados da análise estatística os positivos para brucelose, tuberculose e rinotraqueíte infecciosa e que a correlação é de apenas 0,61 , pode-se admitir, naqueles rebanhos, a ocorrência de outros prováveis agentes de transtornos reprodutivos não considerados neste estudo. Isto pode ser percebido quando se observa que, embora o desvio-padrão seja praticamente igual para ambos os eventos, o coeficiente de variação é 
quase o dobro em transtornos reprodutivos que em prevalência para leptospirose, isto é, a dispersão dos dados é maior, o que sugere indicar variedade de situação entre os rebanhos quanto a transtornos reprodutivos, talvez, resultante de não homogeneidade de condutas de manejo. A amostra, de fato, parece ser mais homogênea quanto à prevalência para leptospirose que para ditos transtornos, visto que há maior proximidade da média e mediana e menor coeficiente de variação na primeira que na segunda.

Tabela 2. Bovinos sororreagentes para L. interrogans, segundo época do ano, e sorovar, microrregião de Parnaíba, PI

\begin{tabular}{lcccccc}
\hline \multirow{2}{*}{ Sorovar* } & \multicolumn{3}{c}{ Seca } & \multicolumn{4}{c}{ Chuva } \\
\cline { 2 - 7 } & $\mathrm{F}$ & $\%$ & $\mathrm{TMG} \overline{\mathrm{X}}$ & $\mathrm{F}$ & $\%$ & $\mathrm{TMG} \overline{\mathrm{X}}$ \\
\hline Australis & 5 & 1,14 & 2,58 & 6 & 1,00 & 3,26 \\
Bratislava & 9 & 2,05 & 3,55 & 15 & 2,47 & 2,84 \\
Autumnalis & 14 & 3,20 & 3,64 & 16 & 2,64 & 2,72 \\
Butembo & 3 & 0,68 & 2,00 & 7 & 1,15 & 1,74 \\
Hebdomadis & 63 & 14,38 & 7,38 & 64 & 10,56 & 4,22 \\
Icterohaemorrhagiae & 6 & 1,37 & 2,13 & 15 & 2,47 & 2,59 \\
Hardjo & 157 & 35,84 & 8,78 & 255 & 42,08 & 6,20 \\
Wolffi & 152 & 34,71 & 5,46 & 127 & 20,96 & 6,35 \\
Shermani & 20 & 4,57 & 3,60 & 39 & 6,44 & 3,95 \\
Patoc & 9 & 2,06 & 3,31 & 62 & 10,23 & 4,70 \\
Total & 438 & 100,00 & & 606 & 100,00 & \\
& $\overline{\mathbf{X}}=4,24 \pm 2,15$ & $\mathrm{Me}=3,57$ & $\overline{\mathrm{X}}=3,86 \pm 1,46$ & $\mathrm{Me}=3,60$
\end{tabular}

*O sorovar registrado foi o que apresentou maior título.

$\mathrm{F}=$ freqüência; $\mathrm{TMG}=$ título médio geométrico; $\mathrm{Me}=$ mediana

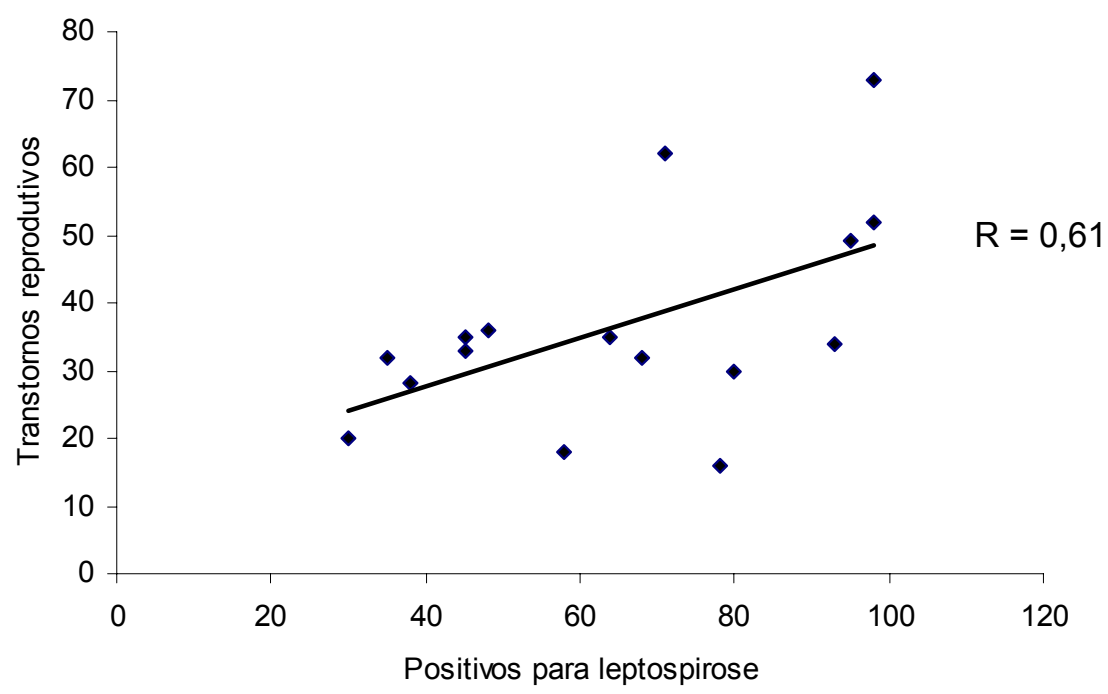

Figura 1. Bovinos sororreagentes para leptospiras x transtornos reprodutivos, Microrregião de Parnaíba, PI, 2001/2002.

Positivos para leptospirose: $\sigma=13,93 ; \mathrm{CV}=0,26 ; \mathrm{Me}=51,97$. Transtornos reprodutivos: $\sigma=13,95$; $\mathrm{CV}=0,46 ; \mathrm{Me}=28,63$ 
Constatou-se que a maior relação entre transtornos reprodutivos e infecção foi observada para Hardjo $(0,69), 1,82$ vezes maior que para Icterohaemorrhagiae $(0,38), 2,03$ vezes maior que Wolffi $(0,34), 2,38$ vezes maior que Bratislava $(0,29)$ e 23 vezes maior que Hebdomadis $(0,03)$ (Tab. 3).

A relação entre a presença de transtornos reprodutivos com a resposta para o sorovar
Hardjo tem sido observada em rebanhos bovinos do mundo todo (Miller et al., 1991; Niang et al., 1995; Lilenbaum et al., 1995; Vasconcellos et al., 1997). Quanto aos demais sorovares, não se encontrou relação entre prevalência da infecção e ocorrência de transtornos reprodutivos. Esses dados sugerem maior virulência do sorovar Hardjo quanto aos transtornos reprodutivos, comparados aos demais sorovares.

Tabela 3. Relação entre transtornos reprodutivos e reação sorológica para leptospirose, segundo sorovar, em bovinos de leite, Microrregião de Parnaíba, PI, 2001/2002

\begin{tabular}{lccccc}
\multicolumn{1}{c}{ Sorovar } & $\mathrm{P}$ & $\mathrm{E}$ & $\mathrm{P} / \mathrm{E}$ & $\mathrm{OR}$ & $\mathrm{EPA}$ \\
\hline Australis & 00 & 11 & 0,0 & - & 0,003 \\
Bratislava & 07 & 24 & 0,29 & 0,98 & 0,005 \\
Autumnalis & 00 & 30 & 0,0 & - & 0,005 \\
Butembo & 00 & 10 & 0,0 & - & 0,003 \\
Hebdomadis & 04 & 127 & 0,03 & 0,07 & 0,010 \\
Icterohaemorragiae & 08 & 21 & 0,38 & 1,47 & 0,004 \\
Hardjo & 284 & 412 & 0,69 & $9,30^{*}$ & 0,015 \\
Wolffi & 95 & 279 & 0,34 & 1,27 & 0,014 \\
Shermani & 00 & 59 & 0,0 & - & 0,007 \\
Patoc & 00 & 71 & 0,0 & - & 0,008 \\
& 398 & 1044 & 0,38 & & -
\end{tabular}

$\mathrm{P}=$ positivo para transtorno reprodutivo, segundo sorovar; $\mathrm{E}=$ exposto (positivos para leptospiras); $\mathrm{P} / \mathrm{E}=$ positivo/exposto; $\mathrm{OR}=$ odds ratio; $\mathrm{EPA}=$ erro-padrão da amostra; $*=$ significativo $(\mathrm{P}<0,05)$.

Quando se procede ao cálculo do risco segundo o sorovar, observa-se, para Hardjo, $\mathrm{OR}=9,30$ significativo; para Wolffi, $\mathrm{OR}=1,27$, não significativo; Bratislava, $\mathrm{OR}=0,98, \quad$ não significativo; Hebdomadis, $\mathrm{OR}=0,07$, não significativo e Icterohaemorragiae $\mathrm{OR}=1,47$, não significativo. Para os demais sorovares, não foi possível calcular OR por ocorrer o valor zero em pelo menos uma das caselas (Tab. 3).

Os resultados deste estudo permitem concluir que, em bovinos de leite da Microrregião de Parnaíba, PI, a infecção por leptospiras é endêmica e está associada à ocorrência de transtornos reprodutivos e pluviometria. A correlação entre transtornos reprodutivos e infecção por leptospiras apontam para a necessidade de controle da infecção pelos sorovares Hardjo, Bratislava, Hebdomadis e Wolffi.

\section{REFERÊNCIAS BIBLIOGRÁFICAS}

ALONSO-ANDIGOBERRY， C., GARCIA-PEÑA， F.J., PEREIRA-BUENO, J. et al. Herd-level risk factors associated with Leptospira sp. Seroprevalence in dairy and beef cattle in Spain. Prev. Vet. Med., v.52, p.190-117, 2001.

ALVES, C.J.; VASCONCELOS, S.A.; CAMARGO, C.R.A. et al. Influência de fatores ambientais sobre a proporção de caprinos sororreatores para a leptospirose em cinco centros de criação do estado da Paraíba, Brasil. Arq. Inst. Biol. São Paulo, v.63, p.11-18, 1996.

ARAÚJO, V.E.M.; MOREIRA, E.C.; NAVEDA, L.A.B. et al. Freqüência de aglutininas anti-Leptospira interrogans em soros sangüíneos de bovinos, em Minas Gerais, de 1980 a 2002. Arq. Bras. Med. Vet. Zootec., v.57, p.430-435, 2005.

CARPIO, J.P.H.; VASCONCELOS, S.A.; HIGA, Z.M. et al. Soropositividade para leptospirose em alpacas criadas no altiplano peruano. Peru. Análise de associação com o índice pluviométrico. Arq. Inst. Biol. São Paulo, v.67, p.171-176, 2000

CARVALHO, S.M. Patologia e patogenia da nefropatia na infecção por leptospiras em ovinos. 2005. 65f. Dissertação (Mestrado) - Universidade Federal do Piauí, Teresina.

CORTEZ, A.; CASTRO, A.M.G.; HEINEMANN, M.B. et al. Detecção de ácidos nucléicos de Brucella spp., Leptospira 
spp., herpesvirus bovino e vírus da diarréia viral bovina, em fetos abortados e em animais mortos no perinatal. Arq. Bras. Med. Vet. Zootec., v.58, p.1226-1228, 2006.

COSTA, E.O. Leptospirose. Abortamentos Infecciosos de Bovinos. In: CONGRESSO BRASILEIRO DE REPRODUÇÃO ANIMAL, 11, Belo Horizonte. Anais... Belo Horizonte, 1995. p.71-79.

COSTA Jr., G.S.; MINEIRO, A.L.B.B; MACEDO, N.A. et al. Anticorpos anti-leptospiras em soros de ovinos da microrregião de Teresina, PI. In: CONBRAVET, 31., 2004, São Luís. Anais... São Luís, 2004.

COVARRUBIAS, A.C.; RUÍZ, V.M.B. Seroprevalencia de leptospirosis bovina en tres municipios del sur de Tamaulipas. Tec. Pec. México, v.33, p.121-124, 1995.

DRUMOND, P.D.; SILVA, E. (Eds). Medicina Baseada em Evidências. São Paulo: Atheneu, 1998. 158p.

ELLIS, W.A. Leptospirosis as a cause of reproductive failure. Vet. Clin. N. Am.: Food Anim. Pract., v.10, p.463-468, 1994.

FAINE, S. (Ed). Guidelines for the control of leptospirosis. 2.ed. Genebra: World Health Organization, 1982. 171p. (WHO offset publication, 67).

FARR, R.W. Leptospirosis. Clin. Infect. Dis., v.21, p.1-8, 1995.

FÁVERO, A.C.M.; PINHEIRO, S.R.; VASCONCELLOS, S.A. et al. Leptospirose bovina - variantes sorológicas predominantes em colheitas efetuadas no período de 1984 a 1997 em rebanhos de 21 estados do Brasil. Arq. Inst. Biol. São Paulo, v.68, p.29-35, 2001.

GALTON, M.M.; SULZER, C.R.; SANTA ROSA, C.A. et al. Application of a microtechnique to the agglutination test leptospiral antibodies. Appl. Microbiol., v.13, p.81-85, 1965.

GUIMARÃES, M.C. Epidemiologia e controle da leptospirose em bovinos: papel do portador e seu controle terapêutico. Rev. Fac. Med. Vet. Zoot. USP, v.19, p.199-206, 1983.

HOMEM, V.S.F.; HEINEMANN, M.B.; HIGA, Z.M., et al. Leptospirose bovina em Uruara, PA, município da Amazônia Oriental. Arq. Inst. Biol. São Paulo, v.67, p. 1-11, 2000.

LILENBAUM, W. Atualização em leptospiroses bovinas. Rev. Bras. Med. Vet., v.18, p.9-13, 1996.

LILENBAUM, W.; SANTOS, M.C.R.; SANTOS, M. R. Leptospirose em reprodução animal. II. Papel do sorovar Hardjo nas leptospiroses bovinas no Rio de Janeiro, Brasil. Rev. Lat. Amer. Microbiol., v.37, p.87-92, 1995.
MACEDO, N.A.; VASCONCELLOS, S.A.; HIGA, Z.M.M. Leptospirose em bovinos leiteiros e trabalhadores no município de Timon, MA. In: COMBRAVET, 24. 1996, Goiânia. Anais... Goiânia, 1996. p.131

MILLER, D.A.; WILSON, M.A.; BERAN, G.W., Survey to estimate prevalence of Leptospira interrogans infection in mature cattle in the United States. Amer. J. Vet. Res., v.51, p.1761-1765, 1991 .

MONTEIRO, C.A.F. Clima. In: Geografia do Brasil. Rio de Janeiro: IBGE, 1968. p.152.

MOLNÁR, E.; NEGRÃO, A.M.G; MOLNÁR, L. Dados sorológicos da leptospirose bovina em algumas regiões do estado do Pará. Rev. Bras. Reprod. Anim., v.23, p.406-407, 1999.

NIANG, M.; WILL, L.A.; KANE, M. et al. Seroprevalence of leptospiral antibodies among dairy cattle kept in communal corrals in periurban areas of Bamako, Mali, west Africa. Prev. Vet. Med., v.18, p.259-265, 1995.

OLIVEIRA, J.M.S.; LOBO, I.M.F. Características clínicoepidemiológicas de leptospirose em Sergipe, período de 2000-2002. In: CONGRESSO SOCIEDADE BRASILDEIRA DE MEDICINA TROPICAL, 39., Belém. Anais... Belém, 2003. p.131.

PLANK, R.; DEAN, D. Overview of the epidemiology, microbiology and pathogenesis of Leptospira spp. in humans. Microbes Infect.,v.2, p.1265-1276, 2000.

SACKETT, D. L.; HAYNES, R. B.; TUGWELL, P. (Eds).Clinical epidemiology. A basic science for clinical medicine. Boston: Little Brown, 1985. 370p.

SANTA ROSA, C.A. Diagnóstico laboratorial das leptospiroses. Rev. Microbiol., v.1, p.97-109, 1970.

SILVA, J.A.; OLIVEIRA, P.R.; CAMARGO, C.R.M., et al. Freqüência de brucelose e leptospirose em rebanhos leiteiros do município de Esmeralda, MG, 1994. In: CONGRESSO BRASILEIRO MEDICINA VETERINÁRIA, 23., Olinda. Anais... Olinda, 1994. p.241

THRUSFIELD, M. (Ed). Epidemiologia veterinária. 2.ed. Zaragoza: Acribia, 2004. 339p.

VASCONCELOS, S.A., BARBARINI JÚNIOR, O., CORTEZ, A., et al. Leptospirose bovina. Níveis de ocorrência e sorotipos predominantes em rebanhos dos estados de Minas Gerais, São Paulo, Rio de Janeiro, Paraná, Rio Grande do Sul e Mato Grosso do Sul, período de janeiro a abril de 1996. Arq. Inst. Biol. São Paulo, v.64, p.7-15, 1997. 